\title{
Ethical Challenges in Refugee Research: Troublesome Questions, Difficult Answers
}

\author{
Claudia Maria Vargas
}

\begin{abstract}
This paper articulates some of the more troublesome questions and ethical challenges that researchers conducting interviews with refugees and refugee service-providers face. The author suggests three thical principles that must be considered when doing qualitative research:a) trust, confidentiality, honesty, responsibility, $b$ ) an active and positive approach to cultural differences, including gender issues, and c) respect for the emotional experiences of victims. By grounding the research process within this ethical practice a delicate balance between the goals of research and the interests of the respondent can be maintained.
\end{abstract}

\section{Précis}

Cet article articule quelques-unes des questions les plus troublantes et posant les défis éthiques les plus épineux auxquelles font face les chercheurs qui menent des entrevues avec les réfugiés et les instances desservants les réfugiés. L'auteur propose la mise en place de trois grands principes éthiques lorsqu'il est procédé à une recherche qualitative: a) confiance, confidentialité, honnêteté, responsabilité, b) une approche active et positive des différences culturelles, incluant les questions de sexage, et c) le respect des expériences émotionnelles vécues par les victimes. En fondant le processus de recherche dans le cadre de la pratique éthique, le dosage subtil peut être obtenu entre les objectifs de la recherche et les intérêts des répondants.

While the decade of the 1980s saw a significant increase in the refugee stud-

Claudia Maria Vargas, Ph.D., is Visiting Assistant Professor, Department of Education, and Core Faculty of the Vermont Interdisciplinary Leadership Education for Health Professionals Program (VT-ILEHP), University of Vermont, VT, USA. ies literature, much remains to be done. Although the literature has focused on particular refugees by country of origin or specific services such as education, health care, or legal status, it is increasingly clear that many of the mostimportant problems arise within point of contact agencies. These agencies must deal with the whole person and family, coordinating a package that may include counselling and provision of a broad spectrum of services (Coles 1990; de Girolamo 1994;Martin 1994;Struwe 1994; Ekblad et al. 994). The delicate condition of refugee families, whatever the country of origin, their tenuous legal status, the day-to-day discrimination many face, and limits on various forms of assistance, mean that service providers and scholars who study refugee service providers and refugees encounter a variety of thorny ethical dilemmas as they go about their respective tasks. While these two sets of ethical concerns-those used when researching refugee service providers, and those when researching refugees-overlap in many ways, the emphasis here is on the ethical challenges researchers face.

This article is based upon two related sets of research, participant observation and interviews of providers and refugees $^{1}$ as part of a larger study in progress on refugee services administration. The participant/observer experience is based on counselling of refugees at a clinic providing psychological services. The other data comes from qualitative research consisting of numerous open-ended interviews with service providers-social workers, health workers, psychotherapists, teachers, principals, attorneys, and community workers-in different parts of the United States, Belgium, Canada, Finland, and Sweden.

The discussion is in three parts. The first partsketches social service needs of refugees. The second considers the rela- tionship between ethics and law. The third examines the ethical issues for refugee service providers as well as the ethical issues for the researcher when interviewing them. The last explores crosscutting ethical principles for the researcher interviewing refugees.

The thesis that emerges is that researchers must establish an ethical framework for addressing issues of:

1) confidentiality, trust, (Dobbert 1984; Punch 1994), honesty and responsibility (Dobbert 1984);

2) cultural sensitivity (Eth 1992; Denzin and Lincoln 1994; Richardson 1994; Stanfield II 1994; De Vault 1995; Baubock 1996); and

3) respect for the victimization experience of refugees ( $\mathrm{Yu}$ and $\mathrm{Liu}$ 1986; Langer 1990; International Migration Review 1996).

\section{What Do We Seek to Research and in What Context?: Refugees' Access to Essential Social Services}

One of the driving forces for researchers who study refugees is the fact that access to social services by refugees in the United States is not only limited, but often inaccessible, particularly for those whose legal status is uncertain. The character of this problem shapes many of the ethical challenges found by researchers in the field. When refugees havenotbeen formally granted asylum, for any number of reasons, they may lack access to health programs. They often have few, if any, funds. "Since 1980, U.S. policy has recognized that many refugees arrive in the United States without money, family, or ways of making a living" (National Research Council 1997, 38). In some cases, families are broken up in the process of flight from the country of origin or because of conditions in the host country. Given the unresolved dilemma of status and rights combined with the baggage inherent in displace- 
ment and exile, doing research with refugees and refugee service providers poses ethical challenges, whether it is the school or hospital or community clinic context.

\section{The Distinction between Law and Ethics: A Critical Understanding for Researchers}

Refugee researchers confront bothlegal and ethical forces that affect both the phenomena that are studied and create complexity for the ways researchers proceed, but law and ethics are not the same, hence the need to understand the distinction. Law is an external check, which seeks to control and constrain action. Ethics, on the other hand, is a set of internal checks derived from one's personal values, professional obligations, or cultural norms that determine behaviour (Cooper et al. 1998). In commentaries on ethics, legal and ethical issues are confused one for the other. In serving this particular group of clients, service providers face both legal and ethical issues. In some cases, legal and ethical norms are compatible, but in other situations doing that which seems ethically appropriate may put refugee workers, and even sometimes the researcher, at the edge of illegality. For example, service providers in California stated their intentions to refuse to follow the mandate of Proposition 187 to report children in the schools who do not have legal status in the United States. In anticipation of the implementation of the law, teachers chose to adhere to their ethical grounding as educators instead of obeying the new law. ${ }^{2}$ Participants of the Sanctuary Movement in the United States, who protected victims of political oppression in Guatemala and El Salvador, anchored their actions on an ethic of justice. In spite of government reprisals, sanctuary movement supporters chose ethics over obeying laws, which denied asylum to victims of political persecution. Refugee workers, as well, are committed to an ethic of service. Immigration officers, legislators, and state or local officials who see themselves as protecting taxpayers against costs of services develop and implement laws with very different premises. Scholars are different from both sets of actors.

It is always important to remember that eliciting or using potentially damaging information may put the researcher in jeopardy of having to disclose it. In 1993, a federal appeals court upheld a contempt of court charge againsta doctoral student. They rejected his claim that researchers are protected from forced disclosure of information by "Scholar's Privilege" which the researcher claimed was covered by the First Amendment to the U.S. Constitution (In re Scarce 1993). The legal implications of this decision may place already vulnerable and victimized refugees further at risk.

Researchers must remember the distinction between law and ethics and evaluate behaviour, including their own, accordingly. Refugee researchers navigate turbulent waters as they try to acquire essential data and the real stories of asylum seekers emerge.

\section{Ethical Challenges and \\ Difificulties in Doing Research with Refugee Service Providers}

The ethical concerns confronted by researchers in conducting interviews with refugee service providers in the areas of health, mental health, social work, and education will be explored in this section. When interviewing those serving refugees, the researcher needs to adhere to the following ethical principles, essential to delve to depths that will allow him or her to see the human face and hear the voices of the refugee experience and its complexity:

a) honesty, trust, and confidentiality;

b) a cross-cultural approach, including gender; and

c) respect for the experience of victimization suffered by refugees.

\section{Honesty, Trust, and Confidentiality Issues}

When working in a politically and fiscally volatile environment and, with a target group that inspires less compassion today, refugee service providers jugglecompounded challenges. Among them is the need to serve a community that has survived perils but may still face threat of deportation. The researcher must be aware that protection of the identity of refugees becomes particularly significant, regardless of the area of service. In emotionally and legal volatile contexts, the researcher needs to be equally careful to protect the identity of the service providers. Clearly the issues of honesty, trust, and confidentiality are critical. Consider the challenges faced by refugees and their service providers from a researcher's point of view.

\section{Health Professionals}

In conducting interviews with nurses and doctors, the researcher has to be conscious of professional standards and professional models (e.g., the medical model) they follow. Because of the health provider's obligation of confidentiality, the researcher can often only work from composite pictures of medical needs and health issues pertinent to refugees or from generalized case studies described by respondents. Specific questions may be asked regarding subgroups, for example, health needs of women, children, men, or specific health issues of certain ethnic groups versus others. However, access to a patient's file, or to a patient, can only be granted with explicit consent. Moreover, health care providers are sometimes unwilling even to put researchers in touch with patients for fear that the refugees will come to doubt their physician's commitment to confidentiality. "Outsiders may be seen as potential threats or possible informants." 3 The researcher must not only decide how far toprobe in these situations, but also how to evaluate responses that are themselves generalizations from particular cases by respondents.

Because health care providers are extraordinarily pressed, accessibility for interviews is often difficult competing for precious time to see patients. Clearly, then, respect for provider's and patients' time, and taking care to be prepared for interviews, will allow the researcher to obtain more useful information and avoid feeling as an intrusive or insensitive. 
While the number of specific examples discussed in interviews may belimited, the researcher may still feel overcome by the obvious human tragedies involved and the overwhelming picture of medical need in the face of a clear inadequacy of available health services. Therefore, interviewsbased on discussions of cases may need to be interpreted in light of othermore general data on the health needs of refugees, e.g., the gynaecological needs of women, men's somatization of trauma, children's bed-wetting as response to witnessing violence. Relevant and accurate information can be obtained if a trusting relationship is established between the researcher and the clinician and if the health care provider's own ethical standing in considering refugees can be accommodated and the concerns of the refugee understood.

\section{Social Workers}

When working in crisis intervention, as is the case in one Canadian group called Visible Minority Women Against Abuse, ${ }^{4}$ social workers spend their time juggling emotionally charged issues. Committed toproviding services to victims of violence, they mustconceal their identities to avoid retaliation by victimizers. Simultaneously, they are entrusted with their clients' safety, complicated when both domestic violence factors and asylum legaldecisions are at stake. In such contexts, researchers have to be alert to the need to maintain confidentiality, in some cases even as to the location of the agency.

Confidentiality, as an ethical principle, applies to research with social workers as well as for other professionals. Some work with refugees who are minors, in which case confidentiality is especially delicate in partbecause there are laws that protect a child's right to privacy and parental authorization is required prior to conducting any interviews. Once again, the researcher will often be obtaining a composite picture of problems encountered by refugees in the host country rather than case studies of named clients. However, the accuracy of the detailed brush strokes on this picture will depend upon the trust es- tablished between the social worker and the researcher based upon assured confidentiality of the identity of the respondent.

Trust is of the utmost importance for the researcher interviewing social workers who need to be assured that their privacy and identity as well as that of their clients will be protected. When this understanding seems tobe assured, the respondents will decide whether and how much to reveal about themselves. This sense of trust is crucial because the respondent is aware that the only real protection he or she has from that point forward is the researcher's ethical commitment to use information prudently and to safeguard that which should remain confidential.

The researcher must also be sensitive to questions that may jeopardize the work of service providers. For example, during interviews with an agency serving abused refugee women, it became apparent that there were boundaries around issues like a recent suicide by one refugeewoman and, in anothercase, threats to counsellors by victimizers. An effort to cross those boundaries appeared likely to fuel latent tensions within the group of service providers. It would also have placed the respondents in ethically dangerous territory.

The fact that social workers often regard themselves as advocates for their clients adds another dimension for the researcher. Torczyner $(1991,127)$ observes: "[W] hat social workers and human rights advocates generally do about social justice becomes the ultimate ethical standard," or what Dobbert $(1984,83)$ calls the "duty to protect the community interests." However, those interviewed say that they "take carenot to press cases or argue for individual clients unless their claims are truly meritorious. ${ }^{5}$ The credibility of workers and their organizations is very important and their"working relationship with the government as well as other organizations depends upon demonstrating good faith and responsible decision-making." Thus, service providers in California and Canada discussed the fine line they walk in helping refugees file asylum claims but discern- ing the legitimate cases to present to immigration officials. It behooves researchers to be alert to the ethical sensitivities these social workers feel as part of the research process. It is a kind of professional empathy that should be present in the relationship.

\section{Educators}

Similarly, educators who have refugee students face a variety of ethical concerns about which researchers must be sensitive. Although there arenospecific guidelines or clearly defined principles for teachers dealing with refugee children, they still face ethical, and even legal, constraints. Because their clients are generally minors, educators are absolutely limited in what they can tell researchers or share with other professionals about their problems. United States federal law (known as the Buckley Amendment) prohibits disclosure of much information about students in the United States and other countries have similar restrictions.

Of course, educators are simultaneously under both legal and ethical mandates to spot and report problems such as potential child abuse. Knowing just how to reconcile these competing demands can be extremely difficult for teachers as well as for those who seek their response to research questions. A cultural canvas rich in colour and texture intensifies these challenges. One of the complicating factors is the educator's need to establish a level of communication adequate toensure understanding and then be able to balance expectations and frustrations that arise. Language or cultural barriers compounds the problem. A teachermay respond to what appears to be a clear case of abuse based on legal mandates, but cultural considerations may make the situation far less clear than itseemed at first.

The actual impact of trauma and violence among children (Boothby 1994; Garbarino and Kostelny 1993) in thenative country plus the complexities of resettlement are extraordinarily difficult to recognize and analyze. Was a fight in the school yard simply misbehaviour? According to respondents, that "some 
fights arose becausechildren came from rival ethnic groups in their country of origin" and, in some cases, because children had heard their parents assert that "the other person's group was responsible for the death of loved ones. ${ }^{16}$ As one Canadian respondent noted,

students may even act out against their family or friends from the home country because they feel they have to be more Canadian than Canadians in order to be accepted. ${ }^{7}$

Respecting confidentiality norms of professional standards test the researcher to draw a composite from different contexts, especially of minors. These examples draw attention to the intertwining of confidentiality and cultural modulations. Similarly, researchers working with teachers must possess a level of ethnocultural competence and communication skills to ask acceptable and appropriate questions as well as to interpret responses correctly.

\section{Problems in Cross-Cultural Communication for Service Providers}

It is not only ethically important for the service providers to operate from a cross-cultural paradigm, it is also for the researcher. The comment from one respondent was typical. "Unless you think in theculture of the people you are seeing, you can miss the boat." 8 When participating in interviews, service providers must be convinced of the interviewer's sensitivity to diverse cultural patterns. Further, the quality of the interview will be determined by the researcher's ability to relate to various ethnocultural and linguistic settings. One cannot expect respondents to both answer questions and also provide interpretative context for the researcher.

Awareness, flexibility, and adaptability are the researcher's keys. Thus, one organization studied in the present research was heavily involved in serving African and Eastern European refugees. The next set of interviews was done with a group that has a strong focus on Ethiopia and Eritrea, though they serve a wide range of refugees. The next organization was predominantly involved in service to Central American refugees. This cultural mosaic becomes particularly significant for researchers. As the social workers interviewed stated plainly: "the dominant paradigm [from which we must work] is Anglo." On the other hand, two respondents noted quickly when discussing this issue that "it is not true that one must be from a particular country or ethnicity to be trusted as culturally sensitive." ${ }^{\prime 9}$ The researcher has the same challenge and an ethical obligation of empathy to be prepared to engage these service providers as well as their clients.

\section{Health Care Providers}

The few sprinkled clinics, principally NGOs that work with scarce human and financial resources, and sometimes community hospital emergency room facilities that provide primary health care for them, regularly encounter culturally complex ethical situations that emerge in conversations with researchers. The cultural dimension plays a significant role both in the doctor-patient relationship and the curative process. It also affects the researcher's understanding of refugee health care. In order to provide effective treatment, health providers have acknowledged "the need to acquire some knowledge of the language and culture as well as an appreciation for the refugee's traditional medicine from the country of origin."10 In this effort, doctors in some regions of the country have embarked in language training with a comprehensive cultural component, including traditionalmedicine practices, religious beliefs, and dialogues with traditional medicine practitioners. ${ }^{11}$ However, in some cases professional ethics may be in conflict with traditional cultural practices.

Ironically, health care providers may even find themselves in an ethical problem without truly understanding it, though with the patient's well-being in mind, according to Western medical practice. A physician may pursue a treatment based on sound medical information, which may have overlooked the cultural significance that a course of action may trigger. Or, if a physician or patient lacks proficient language skills to communicate and depends on family members or culturally untrained translators, the recommended treatmentmay ultimately be altered or reversed. Thus, one respondent reported a tension that arose when one of her clients became upset when a doctor told her she was pregnant.

It seems that she had had her husband translate for the doctor as he was counselling her about birth control. The husband, who wanted his wife to have more children, in part because of cultural beliefs, had simply switched the messages and misinformed both the woman and the physician. ${ }^{12}$

Thus, providers may or may not fully comprehend issues and understandings presented by their patients as was the case in this example. When conducting interviews, researchers need to explore cultural nuances that may be at play and consider how these may differ based upon the specific context whether or not the respondent actually proffers that perspective. The ethical obligation of empathy applies even in those settings in which, indeed particularly in those cases where respondents feel but may not articulate difficulties.

There are also questions about the responsibility that health providers have to understand cultural norms of their patients when disclosing diagnoses and prognoses or when consulting on treatment options. Muller and Desmond (1992) discuss ethical conflicts involved in a case of a Chinese woman who died from cancer. The doctors were careful to consult on the best medical treatment for the terminally-ill patient. However, operating from a Western medical paradigm, they focused on informing the patient of her terminal condition and offering her the option of a less than aggressive treatment. That was totally in contradiction with the ethnocultural beliefs and practices of the family. Because the patient was 49 years old, she was considered much too young to die particularly for a culture, which reveres old age as a sign of good fortune. Furthermore, informing the patient of her dire condition signified intensification of her suffering. It is 
a Chinese tradition that when someone is ill he or she needs protection, including from bad news. In this case, several ethical issues were at play: disclosure of diagnosis and prognosis, and differing or conflicting medical practice with cultural values and norms (Muller and Desmond 1992, 327).

A researcher in such a case has two problems. The first is empathy for the practitioner and patient. The second has to do with what information the researcher might feel moved to offer to the service provider. The physicians may also face dilemmas if referral for consultation or treatment is indicated, since there are risks that the patient may fear disclosure of legal status and thus avoid treatment. One of the service tensions at play for the researcher in health care or in any other service area is how to manage information that touches on immigration status in law.

Indeed, even when the researcher and the practitioner have the best intentions and understand the cultural dimension of an issue, ethical dilemmas emerge that may have legal consequences. Since service providers operate from professional ethical standards as well as legal norms, traditions they encounter may challenge them in both arenas. Service providers may have to reckon with cultural traditions at odds with ethical and legal norms. Female genital mutilation, a practice of Muslim societies in the Middle East, Africa, and Asia, is now also perpetrated in Europe and the United States. Service providers, teachers, and social workers, are responsible for reporting it as child abuse while physicians are challenged by mothers who want their daughters excised or by patients with gynaecological complications as a result of infibulations. In some cases, physicians getrequests from women whowant tobe sewn after delivery. Meanwhile, an Atlanta obstetrician "has been quietly performing what he calls 'female circumcision reversals,'" (Hansen and Scroggins 1992,1) to avert possible cultural collision with community or family members still adhering to the tradition.

\section{What is clear is that}

female circumcision -or whathealth experts prefer to call female genital mutilation-... is presenting medical, legal and ethical problems for American hospitals and courts. (Hansen and Scroggins 1992, 1)

Although acceptance of this practice is still debated as supporters claim respect for traditional cultures, the United Nations and others condemn it as a violation of a human right or a child's right. However, medical practitioners deal with the dilemma of a tradition in conflict with a medical practice. Since physicians operate from professional ethicalstandards, but on the margins of legal mandates, respecting traditions that are at odds with their ethical and legal responsibility may create conflict and no easy solutions. The obvious ethical tension for the researcher emerges in managing situations in which the professional or legal norms of the care giver are at odds with the patient's, particularly if the researcher speaks with both parties.

\section{Mental Health Providers}

There has been a movement in the last fifteen years to consider the cultural issues of psychotherapy in order to really understand the client, more so when the client is a refugee (Nguyen 1980; Martin-Baro 1988; Ramirez 1991; Wing Sue and Sue 1990; Farias 1990; Tseng and Hsu 1991; Lynch and Hanson 1992; Marsella et al. 1994). This approach has important impacts in this field in light of the fact that all refugees cannot be lumped into one ethnocultural group, but come from diverse backgrounds. In fact, there is a clear sense in which the researcher may face more than one constructed reality: the set of interpreted realities that therapist/respondents possess and the multiple constructed realities that may be present among a group of refugee/respondents, even if they are compatriots.

To this general principle of cultural understanding in counselling must be added other ethical issues that are critical when working with refugees in particular. First, trust is fundamental since many refugees have been tortured or persecuted and may suffer from PostTraumatic Stress Disorder (PTSD) (Doerr-Zegers et al. 1992; Eth 1992; Kinzie and Boehnlein 1993). Second, as it is true with other types of providers, confidentiality needs to be assured, though there is a special situation when there are issues of suspected child abuse or when a client is a threat to himself or herself or others. "Trust and confidentiality are the most important aspects of the therapeutic alliance" (Kinzie and Boehnlein 1993, 101).

For refugee patients, their first encounter with a mental health provider may come only at the strong recommendation by a physician. "They maybring to this encounter cultural baggage that holds that mental health is only for those who are 'crazy. ${ }^{\prime \prime 13}$ A trusting environment through an empathicear is needed to break down cultural barriers and open the door to subsequent visits for actual treatment. At this time care must be taken to assure refugees that any written information is strictly for the purpose of creating a clinical history record, and that strict confidentiality will be observed. In the case of Vietnamese people for whom saving face in front of their community, it is especially important for the service provider and for the researcher to establish trust and safeguard confidentiality.

Third, therapists and researchers who work with them must face extraordinary human tragedies due to trauma, torture, and dislocation of refugees that may press them to become social activists or at least to lose their clinical and analytic perspective. Over identification with human suffering may impede the therapist from maintaining the necessary distance and from facilitating the sharing of information by the refugee client. Thus,

\section{Continuing to feel therapeutically competent and ethically grounded, yet maintaining the personal strength and balance to treat trauma- tized patients, pose major challenges for therapists. (Kinzie and Boehnlein 1993, 102)}

The same is true for researchers who conduct interviews with refugee service providers often feel compelled to be- 
come advocates as they face the emotional strain of the numerous heartwrenching stories, but who alsoneed to maintain the distance necessary to do theanalysis. There are those who seek to play both roles but these positions present different ethical framework; it is essential to be aware which ethical stance, activist or researcher, is appropriate in a given context (Denzin and Lincoln 1994).

As with physicians, researchers must be aware of the psychotherapist's concern with confidentiality in a crosscultural context and be ethically comfortable with how to deal with it. Like physicians, the reaction of some mentalhealth care respondents is to provide the researcher with composite pictures of the traumas encountered by refugees. However, in order to get even that far, the researcher's credibility must be established. The therapist and the researcher must establish a level of trust. The clinician must be confident that the interviewer understands the enterprise and its cross-cultural aspects well enoughnot to press questions the therapist cannot answer or reveal information that might place the clinician or the client at risk. There is the confidentiality owed to the client, of course, but there is also the often unstated obligation contracted between the therapist and the researcher of informed empathy grounded in assured confidentiality.

In order for the therapist to develop that psychological contract with the researcher, he or she will seeksignals that indicate cultural sensitivity in the investigator. Since cultural considerations are so critical to the therapist's work, failure to evidence such sensitivity makes it nearly impossible to have effective conversations. Those difficult few moments in interviews can be overcome by careful explanation of the project for which data are sought, introductions that ensure discussion of the experience of the researcher, and indications of other organizations and sites where research has already been done. Brief comments by the researcher may demonstrate understanding of some of the difficulties encountered by mental health providers. For example, sensitiv- ity to the emotional scars of violence, war, and torture may signal the therapist that the researcher has an informed empathy to refugee-specific syndromes and experiences as well as signal commitment to confidentiality.

\section{Educators}

Ethical and legal norms pervade the school setting. However, although these two dimensions emerge simultaneously they are, for reasons discussed earlier, separate. Both sets of factors are rendered increasingly complex by different cultural tones and shades. The ethnic mosaics of some schools place demands on educators not to make uninformed assumptions about culturally-based behaviours or attitudes. Those factors also complicate the task of the researcher interviewing educators. As with other service agencies, information provided must be respectful of minors' rights, privacy protection laws, and professional ethics codes. And, as with others in the refugee service sector, the quality of information will be contingent upon the researcher's cross-cultural knowledge and the informed empathy of the educational enterprise. The following case intends to illustrate a dilemma between cultural practices and professional ethical and legal mandates.

In Canada, a respondent reported the case of a child who came to school with suspicious blue marks on his throat.

The teacher was about to report the case when she remembered hearing in a multicultural workshop about the Chinese practice of "coining" as a home remedy against colds. Before calling the child protection authorities, she called the Multicultural Liaison Officer who contacted a Chinese doctor, who confirmed that, in fact, it was "coining" and not a case of child abuse. $^{14}$

This particular case had a positive resolution, but respondents havenoted less desirable outcomes in other instances. However, an ESL teacher in the United States shared a different experience: "Weknow it's coining. We tell the principal it is coining, but we still have to report it." 15 The principal in this con- text was operating from a legal framework as was the teacher mentioned earlier. However, the researcher in both cases needs to be respectful of the alternative course of action chosen in differentsettings. Clearly, a dilemma emerges when culturalinterpretations may have to be subordinated to legal constraints.

A researcher in such a context should be sensitive to and respectful of various cultural healing practices. Because teachers operate under legal obligations, reporting cases of suspected child abuse becomes necessary. However, precipitous assessment by a researcher about this case could be both inaccurate and damaging. If such a case appears shocking to the researcher, asking the interviewees for an explanation and listening with empathy may be a sound course of action.

\section{Gender Sensitivity}

Considering issues specifically related to gender is vital when conducting research with refugees, given that more that 80 percent of the refugee population are women and children (Martin 1995; Brown et al. 1996). However, although women and girls have a significant representation, they have remained virtually invisible in terms of their specific issues and needs (CamusJacques 1990; Martin 1995). There is a dearth of research on refugee women, especially in the area of health, education and training, and employment. Victims of persecution, both physical and sexual abuse, women often also carry the burden of safeguarding their families, often at the expense of their own well being. A complicating factor is the reality that once in a host country, some refugee women remain withdrawn, silent, and virtually invisible. It is therefore difficult for researchers to address their situation and its importance. Their special vulnerability and sensitivity intensify the ethical commitments that researchers must bring to their tasks.

Among service providers, some embrace serving certain groups of refugees such as children or persons from particular ethnicities. Others choose to focus their efforts to help female victims of violence. When dealing with women, 
gender issues and cross-cultural tensions can trigger issues of trust and confidentiality. Male researchers may be viewed with suspicion in an organization that, for example, serves abused women. A male researcher may thus have to gain their trust and confidence in the initial stage of the interview before relevant information is shared. This was certainly the case with a male in the research team when interviewing service providers in one of the Canadian groups. Once he communicated his trustworthiness, the female respondents relaxed during the interview as the interaction proceeded based on mutual "respect, noncoercion [or] manipulation" thus operating from a contextualized consequentialist model (House 1990; Smith 1990, in Denzen and Lincoln 1994, 21-22). A researcher, male or female, who demonstrates respect, sensitivity, empathy, and understanding of the volatile working climate, and sensitivity to gender issues can reduce suspicion and create a trusting and open environment (Fonow and Cook 1991; Collins 1991, in Denzen and Lincoln 1994). That is, the concept of informed empathy must be expanded to include the gender dimension.

Female researchers also face gender issues. They may have to deal with the risk of over identification with issues pertinent to women such as abuse, violence, and rape, risking clarity of her role as a researcher. That is true, notwithstanding feminist and critical research theory consideration of research as "activist research." Still, over identification with gender issues may lead to overlooking other relevant issues for refugees, including gender cultural nuances. For example, in interviewing refugee service providers, the depth of understanding of males may be underestimated. A male refugee service provider explained "refugees from cultures different from mine prefer to deal with me rather than others from their own culture, because they know they can trust me." ${ }^{16}$ Transcending genderbased lines may be required to avoid compromising the necessary distance tounderstand and analyze the complexity of issues at work. At the very least, it is necessary to identify the ethical stance from which the researcher is operating beforehand, (Denzin 1989, 26164, in Denzin and Lincoln 1994; Riessman 1987; Hertz 1996) "in order to produce less distorted accounts of the social world" (Hertz 1996, 5).

In operating from a cross-cultural model the researcher is challenged as he or she becomes what Renyi $(1993,204)$ calls a "border dweller," a person who can traverse frontiers dancing to the tunes of each and all of them while capturing the various perspectives. This calls on the researcher to interview a variety of different kinds of service providers to truly understand their experiences, to assure trustworthiness and transferability (Kincheloe and McLaren 1994). It also means a particular need to test evaluations of observations by being attentive and sensitive to the cultural dimension and the history of victimization of women and children under study (Leavitt and Fox 1993; Mareenn 1993; Marsellaet al. 1994; Igoa 1996). Its kaleidoscopicnature requires the researcher to acquire an ample collection of culturally-tinted glasses obtained from various service providers prior to a final evaluation.

\section{Refugees and Researchers: Ethics of Social Science Research}

Beyond the field-specific issues raised earlier, the opportunity to interview refugees is unique in other ways. This section considers crosscutting issues and special problems. An essential point to maintain is to carefully evaluate how much personal information to seek. Since these are people who have experienced real terror, have been victimized, tortured, or persecuted, revealing their identity is a delicate issue. In addition, they have to feel as though they have a stable base on which to operate, and, thus, may be anxiety ridden about potential threats for their family or themselves in the host country or for those left behind in their country of origin. Thus, they must make an initial judgement about the researcher's promise as an ethical professional. There is an additional ethical dimension present, at least an implied aspect, because inter- viewers may be introduced or present themselves as authority figures, thus intensifying the pressure felt by refugees. Quite apart from whether the researcher is associated with an agency, respondents may fear that the work is sponsored or indirectly controlled by the authorities. Moreover, refugeesfrom countries where university faculty hold great prestige and authority may be far more threatening than they know. Trust, therefore, plays an important role. It may be an even greater issue in the current political climate characterized by increased hostility toward refugees and immigrants generally.

\section{A Different Cut at Trust and Confidentiality}

Upon sharing the written interview with one of the respondents, a refugee service provider, who was herself a refugee, becamemost concerned about sharing in writing a tragic story that was so particular that it could be identified by the family of the victim. Ethically, to preserve the trusting relationship, it was essential to appreciate her concerns over confidentiality of the family as well as her own, although the researcher had assured her that her identity would not be revealed. She needed additional assurances that some of the unique details of the story would be altered to avoid revealing the location of the tragedy. Due to the intensity of the tragedy of her family, her anxiety was so intense that to allay her fears, the researcher invited her to make the necessary changes. To put her further at peace, the researcher asked her to generate a fictitious name with which she felt comfortable. Theyboth worked together on different names until the refugee chose one.

The fact that research that may involve minors is particularly sensitive was mentioned earlier in connection with schools and teachers. However, there are additional dimensions to be considered that apply more generally. Obviously, confidentiality and parental consent becomes even thornier than with adults. First, parental consent can be a curious problem in dealing with refugees if the researcher doesnotspeak 
the parents' native language. Since children tend to learn the language of the host country faster than their parents, the parents often rely upon them as interpreters. Refugee services workers indicate that "children, particularly teenagers, use the language dependence as a power lever against parents." Thus, the ethical problem arises as to whether parents who are granting or denying consent fully understand the research and its intended uses.

Second, although there is an ebb and flow of child refugees, depending upon the political conflict in a country and the number of orphan children it generates, parental consent is even more complicated. When there are homeless refugee orphans, suffering from post-traumatic stress disorder, who have neither legal status or guardians, a problematic situation in safeguarding the minors' confidentiality in a context in which they lack legal status (Olivas 1991), is more complicated. The following cases may illuminate the point.

A Guatemalan 13 year old female had traversed throughherwarstrickencountry, Mexico, and the United States when, upon arrival in San Diego, California, some men picked her up and transported her blindfolded to a club somewhere in Los Angeles where she was forced to engage in prostitution. Although the men looked Hispanic, they spoke an entirely different language.17

The assumption made by the social worker was that" the girl had been kidnapped and sexually abused by men from a Middle Eastern country ." For this young girl the sexual abuse committed in such circumstances and in a context where the language was foreign to her intensified the trauma triggering a deep depression. The array of issues presented to the researcher considering such a case is substantial, intense, and complex. Even so, failure to address such cases in order to avoid the dilemmas both undermine the methodological and conceptual integrity of the work and leaves critically important date unreported and unanalyzed.

The severity of the trauma experienced by refugee minors as an aspect of being orphaned can make it impossible to interview them. The social worker indicated that "the girl was in a severe depression and in a fragile emotional. state," although in a temporary haven at a Los Angeles shelter for refugee children. Given the Catholic upbringing and stem Latin tradition regarding virginity, this case illustrates the complexity of trust, confidentiality as well as the need for cultural understanding. Although this girl's legal protection as a refugee minor was not defined, given that there was no legislation protecting minors who are refugees, the social worker was operating from an ethical standard, one that a researcher needs to respect. In such cases, the researcher must determine how to treat the second person report of the case in terms of its validity and with respect to possible disclosure of identity.

\section{Other Aspects of the Cultural} Sensitivity Requirement

While the importance of cultural sensitivity was noted earlier, there are som additional dimensions to consider. For one thing, special attention must be paid to avoid interpretative or analytic generalizations based on what may appear, on the surface, as an ethnoculturally homogeneous group because the refugees may come from the same country or neighbouring regions in the world. It is helpful to have knowledge not only of a language and of the various cultures represented among the interviewees but also of the sociopolitical situation from which they come. In the absence of that knowledge, the researcher requires not only linguistic translation but also cultura interpretation. Sensitivity on the part of the researcher to cultural modulations, and to different verbal and nonverbal communicationmay allow the interviewees to work through difficult topics or questions. In this manner, the researcher may avert situation where interviewees close up or provide evasive responses. As Oenzin and Lincoln (1994,

12) pose, "Any gaze is always filtered through the lenses oflanguage, gender, social class, race, and ethnicity."
Moreover, the researcher who overlooks cultural differences may not ask questions that elicit information on the subjective experience of subgroups based on class, race, gender, or educational experience. In one group interviewed, for example, former military men asserted themselves as spokespersons for the group. Of course, this created a tense climate in which the researcher had to avert possible "political" conflict during the interview process. Another consequence may be that those who have been oppressed will once again assume a subservient or passive role. Thus, assuming that all refugees are having similar experiences, or thatthey are a cohesive group, presents possible misunderstandings

with consequences even for future researchers (Yu and Liu 1986). Clearly, it is important to prepare one's cultural know ledge base in preparation for such interviews.

Often the intra-group differences are as diverse as the inter-group contrasts. Fo example, indigenous groups from Guatemala may speak one of the 22 Mayan languages and may have no knowledge of Spanish. Yet Mayan groups may be unable to communicate with each other in a common language. In other situations, for" campesinos" the political conflicts leading to the war in E Salvador may be totally foreign to them even though they had endured persecution and were ousted from their land. Notwithstanding their political naivete, they may be reticentto speak in the presence of others from their homeland because of possible retribution, even if they do not understand exactly why.

When asking possibly threatening questions that may later lead to confrontation or retaliation from others, it is particularly critical for the researcher to be alert to cues from refugees. In such circumstances the researcher's knowledge of cross-cultural nonverbal communication is particularly useful. Furtive looks may suggest that a question is stepping on fragile ground. During an interview of Central American refugees, a silence prevailed along with compromising looks. Later, one of the 
refugees explained to the researcher, IIWe could not talk because Juan (a fictitious name) was in the military in EI Salvador and we are still afraid he may retaliate here in the United States. illS Still, respondents who have been oppressed, can be given a voice through the proper interpretation of nonverbal communication and learning lias a scholar how to speak about aspects of [a] community which lacks a spoken language ${ }_{\text {II }}$ (Wichroski 1996, in Hertz $1996,8)$. In this case, the researcher would be wise to consider the politics of the historical period in EI Salvador while also being in tune to the IIplurality of cultures" (Quantz 1992,483) among a group of refugees. Kincheloe and McLaren (1994, 152) support Louis Dumont's view that II cultural texts need to be viewed simultaneously from the inside and from the outside. ${ }_{\text {IS }}$ Such a context demands from a researcher linguisticcompetence, knowledge of crosscultural communication, and respect for the historicity of the respondents.

The researcher who keeps in mind the culturally assigned gender roles in particular cultures, even if in disaccord with the host culture or his or her own, may find that such awareness may enhance participation. For example, asking males about their homelessness may lead to embarrassment and pose a threat to their male self-image IIbecause they are unable to provide for themselves or their families.ll19 This was the case with the Central American males who revealed their lack of shelter in the interview context: IIWe live under the freeway overpass or abandoned downtown buildings.1I20 Females, on the other hand, may be reluctant to speak at all or may consistently defer to males, but when a space is opened for them, are willing to share their struggle to have

IIteachers listen to our concerns for our children. ${ }_{\text {" Cumming and Gill }(1991,10)}$ present a similar situation in Canada for immigrant mothers from India regarding IIpressures to communicate with their children's teachers.1I Service providers interviewed for this research indicated, for instance, that some refugee women IIwould rather die"2l than reveal discord in their family that led to

Refuge, Vol. 17, No.3 (August 1998) abuse. Informed empathy can help the researcher pose specific questions while conveying an understanding of such experience. Similarly, in order to understand responses by refugees, the researcher must evidence sensitivity to these dimensions or risk shallow responses.

According to critical ethnography theory, one of its purpose is emancipation of the marginalized group through multivocality in which self-articulation can emerge (Quantz 1992). With this particular group, it was important to recognize the plurality of cultures as well as the struggle to make sense out of the homelessness experienced by males and the frustration of the mothers with the school. The issue of trustworthiness, regarding II the credibility of portrayals of constructed realities ${ }_{\text {II }}$ (Kincheloe and McLaren 1994) and the similarity of contexts compared, is essential when dealing with highly vulnerable individuals.

\section{Triggering Repressed Memories:}

\section{Respecting Emotional}

\section{Vulnerability}

Vulnerable and oppressed respondents pose special challenges to the researcher. IIHow does the knowing subject come to know the Other? How can researchers respect the perspective of the Other and invite the Other to speak?1I (Kincheloe and McLaren 1994, 152). Once refugee respondents or refugee service providers actually open up and begin to speak candidly, they may undergo a process of release. Although the best interview plans may go awry, it is essential to permit the commentary to unfold even though some of the information that emerges may be upsetting to the researcher, as when graphic stories of abuse emerge concerning family violence, in detailed descriptions of war atrocities, or in stories of abuse during flight to asylum. The interview plan must accommodate the nature of the pressures at work in the lives of respondents.

At the same time, such circumstances require the researcher to maintain an ethically supportable balance between empathy and analytic distance. He or she maybe easily overwhelmed with the cathartic reaction triggered by the interview process with people who are so anxious to tell their stories. The agony of a silenced rape by a military officer may be anguishing a quiet young woman while a young man seeks to share his story of torture by the Salvadoran military: "I was tortured with electric shock on a metal mattress.lI22 Empathy and silence by the researcher as a form of respect for that emotional experience may allow for validation and support from other refugees in the group as well as break the silence and alienation that may lead to selfunderstanding (Kincheloe and McLaren 1994).

The heart-wrenching stories, however, can easily co-opt the researcher. Social activism takes on a new meaning as the possibility of becoming an agent of change tempts the researcher to divert from pursuing research. At times like this, operating from a well-established ethical framework becomes really important. A helpful reminder for the researcher is the relevance of developing a theoretical poin of view on refugee issues as opposed to becoming diffused and absorbed by the insurmountable needs of this group of people. Nonetheless, it is the ethical framework that allows the researcher to be more effective

in documentation and interpretation of the stories, although it does not preclude being involved in refugee issues. However, it is essential to know which role one is taking at any given time and to not engage in activities that would damage one's credibility or analytic perspective as a researcher (Denzin and Lincoln

1994; Hertz 1996). In other words, defining one's role as a researcher or as a refugee advocate, a priori, is necessary in order to operate from the appropriate ethicalframework, or as Hertz (1996,S) articulates, IIit is essential to understand the researcher's location of self. II

Notwithstanding, when operating from a critical research framework, it is assumed that both roles are intertwined, the research is II activist research" (Quantz 1992, 498) and therefore inherently transformative. However, a criticism is that it has been less emancipatory for the respondents, instead 


\section{References}

Baubock, Reiner. 1996. "C'..JItural Minority Rights for Immigrants" International Migration Rev;ew XXX, :10. 1,203-50.

Boothb\}., Neil. 1994. "frauma and Violence Among Refugee Children." InAmidst Peril Among Refugee Children." InAmidst Peril
and Pain: The Mental Health and Welland Pain: The Mental Health and WellBeing of the World's Refugees, edited by Anthony J. Marsella, Thomas Bornemann,
Solvig Ekblad, and John Orley, 239-59. Washington, DC: American Psychological Association.

Brown, Lester R, Christopher Flavin, and Hal Kane. 1996. Vital Signs, 1996: The Trends that are Shaping our Future. Trends that are Shaping our Future. Washington, DC: World Watch Institute.
amus-Jacques, Genevieve. 1990. "Refugee Camus-Jacques, Genevieve. 1990. "Refugee
Women: the Forgotten Majori ty." In RefuWomen: the Forgotten Majori ty." In Refugees and International Relations, edited by Gil
Loescher and Laila Monahan. Oxford: Clarendon Press.

Coles, Gervase. 1990. "Approaching the Refugee Problem." In Refugees and International Relations, edited byGil Loescher and Laila Monahan. edited byGil Loescher

Collins, Patricia H. 1991. Black Feminist Thought: Knowledge, Consciousness and the Politics of Empowerment. New York: Routledge.

Cooper, Phillip J. 1998. "Law and Ethics: Legal Accountability and Ethical Accountability." In Public Administration for the TwentyFirst Century, edited by Phillip Cooper and Associates. New York: Harcourt Brace.

Cumming, Alister, and Jaswinder Gill. 1991. "Motivation or Accessibility? Factors in the Decision of Indo-Canadian Women to Pursue ESL Literacy Instruction." Paper presented at the annual meeting of the American Educational Research Association, Chicago, April 1991.

deGirolamo, Giovanni. 1994. "Primary Health Care of Refugees." InAmidst Peril and Pain: The Mental Health and Well-Being of the World's Refugees, edited by Anthony J. World's Refugees, edited by Anthony J.
Marsella, Thomas Bornemann, Solvig Marsella, Thomas Bornemann, Solvig on, DC: American Psychological Association.

Denzin, Norman K. 1989. The Research Act. 3d

d. Englewood Cliffs, NJ: Prentice Hall.

Denzin, Norman K., and Yvonna S. Lincoln. 1994. "Entering the Field of Qualitative 1994. "Entering the Field of Qualitative
Research." In Handbook of Qualitative Research, edited by Norman K. Denzin search, edited by Norman K. Denzin and Yvonna S. Lincoln, 1-17.

De Vault, Marjorie L. 1995. "Ethnicity and Expertise: Racial-Ethnic Knowledge in Sociological Research." Gender and Society 9 , no. 5, 612-31.

Doerr-Zegers, Otto, Lawrence Hartmann,

Elizabeth Lira, and Eugenia Weinstein.
1992. "Torture: Psychiatric Sequelae and Phenomenology." Psychiatry 55, no. 2 (May): 177-84

Dobbert Lundy, Marion. 1984. Ethnographic Research: Theory and Application for Modern Schoolsand Societies. New York, NY: Praeger Publishers.

Ekblad, Solvig, Bengt-Erik Ginsburg, Bengt J ansoon, and Lennart Levi. 1994. "Psychosocial and Psychiatric Aspects of Refugee Adaptation and Care in Sweden." In Amidst Peril and Pain: The Mental Health and Well-Beingofthe World's The Mental Health and Well-Beingofthe World's
Refugees, edited by Anthony J. Marsella, Refugees, edited by Anthony J. Marsella,
Thomas Bornemann, Solvig Ekblad, and John Orley, 275-92. Washington, DC: American Psychological Association.

Eth, Spencer. 1992. "EthicalIssuesin the Treatment ofTraumatized Refugees." Journal of Traumatic Stress 5, no. 1, 103-10.

Farias, Pablo. 1990. "El modelo biomedico frente a la tradici6n popular en los Altos de Chiapas" (The Biomedical Model Versus Popular Tradition in the Chiapas Highlands). Boletin Mexicano de Historia y Filosofia de la Medicina no. $13,60-72$.

Fonow, Mary M., and Judith A. Cook. 1991. "Back to the Future: A Look at the Second Wave of Feminist Epistemology and Methodology." In Beyond Methodology: Feminist Scholarship as Lived Beyond Methodology: Feminist Scholarship as Lived
Research, edited by Mary M. Fonow and Research, edited by Mary M. Fonow and
Judith A. Cook, 1-15. Bloomington, IN Indiana University Press.

Garbarino, James, and Kathleen Kostelny. 1993. "Children's Response to War: What Do We Know?" In The Psychological Effects of War and Violence on Children, edited by Lewis A. Leavitt and A. Nathan A. Fox, 23-39. Hillsdale, NJ: Lawrence Erlbaum Associates, Publishers.

Hansen, Jane, and Deborah Scroggins. 1992. "Female Circumcision: U.S., Georgia Forced to Face Medical, Legal Issue." Atlanta Journal Constitution, November 15, Section A, pp. 1 and 10.

Hertz, Rosanna. 1996. "Introduction: Ethics, Reflexivity and Voice." Qualitative Sociology 19, no. 1, 3-9.

House, E. R 1990. "An Ethics of Qualitative Field Studies." In The Paradigm Dialog, edited byEgonG. Guba, 158-64. Newbury Park, CA: Sage.

Igoa, Cristina. 1995. The Inner World of the Immigrant Child. New York: St Martin's Press.

In re Scarce. 1993. 1993 WL 356392 (9th. Cir.). International Migration Review. 1996. "Ethics,

Migration, and Global Stewardship. " Vol. XXX, no. 1.

Kincheloe, Joe L. and Peter L. McLaren. 1994. "Rethinking Critical Theory and Qualitative Research." In Handbook of Qualitative
Research, edited by NormanK. Denzinand Yvonna S. Lincoln. Thousand Oaks, CA: Sage Publications.

Kinzie, J. D., and J. K. Boehnlein. 1993. "Psychotherapy of Victims of Massive Violence: Countertransference and Ethical Issues." American Journal of Psychotherapy 47, no. 1 (Winter): 90-102.

Langer, Beryl. 1990. "From History to Ethnicity: El Salvadoran Refugees inMelbourne." Journal of Intercultural Studies II, no. 2, 1-13.

Leavitt, Lewis A., Nathan A. Fox, eds. 19)3. The Psychological Effects of War and Vio!ei!ce on Children. Hillsdale, NJ: Lawrence Erlbaum Associates, Publishers.

Lynch, Eleanor W., and Marci J. Hanson. 1992. Developing Cross-Cultural Competence: A Guide for Working with Young Children and Their Families. Baltimore, MD: Paul H. Brookes Publishing Co.

Mareenn, Lea. 1993. Salvador's Children: A Song for Survival. Columbus, OH: Ohio State University Press.

Marsella, Anthony J., Thomas Bornemann, Solvig Ekblad, and John Orley. 1994. Amidst Peril and Pain. The Mental Health and Well-Being of the World's Refugees. Washington, DC: American Refugees. Washington,
Psychological Association.

Psychological Association.
Martin, Susan Forbes. 1994. "A Policy Perspective on the Mental Health and Psychosocial Needs of Refugees." In Amidst Peril and Pain: The Mental Health and Well-Being of the World's Refugees, edited by Anthony J. Marsella, Thomas Bornemann, Solvig Ekblad, and John Orley, 69-80. Washington, DC: American Psychological Association.

- 1995. Refugee Women Atlantic High lands, NJ: Zed Books Ltd.

Martin-Baro, Ignacio. 1988. "La violencia politica y la guerra como causas del tra uma psicosocial en El Salvador" (Poli tical Violence and War as Causes of Psychosocial Trauma in El Salvador). Revista de Psicologia de El Salvador, no. 7, 123-41.

Muller, J. H., and B. Desmond. 1992. "Ethical Dilemmas in a Cross-Cultural Context: A Chinese Example." Western Journal ofMedicine 157, no. 3, 323-27.

National Research Council. 1997. The New Americans: Economic, Demographic, and Fiscal Effects of Immigration. Washington, DC: National Academy Press.

Nguyen, Dang Liem. 1980. "The Resettlement of Vietnamese Refugees." Journal of AsianPacific and World Perspectives 4, no. 1, 3950.

Olivas, Michael A. 1991. "'Breaking the Law' on Principle: An Essay on Lawyers' Dilemmas, Unpopular Causes, and Legal Regimes." University ofPittsbu rgh Law Review 52 (Summer): 815-57. 
Punch, Maurice. 1994. "Politics and Ethics in Qualitative Research." In Handbook of Qualitative Research, edited by Norman K. Denzin and Yvonna S. Lincoln, 83-97. Thousand Oaks, CA: Sage Publications.

Quantz, Richard. 1992. "On Critical Ethnography (with Some Postmodern Considerations)." In The Handbook of Qualitative Research in Education, edited by $\mathrm{M}$. LeCompte, W. Millroy, and J. Preissle, 447-505. New York: Academic Press.

Ramirez, Manuel III. 1991. Psychotherapy and Counseling with Minorities: A Cognitive Approach to Individual and Cultural Differences. New York: Pergamon Press.

Renyi, Judith. 1993. Going Public: Schoolingfor a Diverse Democracy. New York: The New Press.

Richardson, L. 1994. "Writing: A Method of Inquiry." In Handbook of Qualitative Research, edited by Norman K. Denzin and Yvonna S. Lincoln, 516-29. Thousand Oaks, CA: Sage Publications.

Riessman, C. K. 1987. "When Gender is not Enough: Women Interviewing Women." Gender and Society 1, 172-207.

Smith, L. M. 1990. "Ethics, Field Studies, and the Paradigm Crisis." In The Paradigm Dialog, edited by Egon G. Guba, 139-57. Newbury Park, CA: Sage.

Stanfield II, John H. 1994. "Ethnic Modeling in Qualitative Research." In Handbook of Qualitative Research, edited by Norman K. Denzin and Yvonna S. Lincoln, 175-88. Thousand Oaks, CA: Sage Publications.

Struwe, Goran. 1994. Training Health and Medical Professional to Care for Refugees: Issues and Methods." In Amidst Peril and Pain: The Mental Health and Well-Being of the World's Refugees, edited by Anthony J. Marsella, Thomas Bornemann, Solvig Ekblad, and John Orley, 263-74. Washington, DC: American Psychological Association.

Torczyner, Jim. 1991. "Discretion, Judgement, and Informed Consent: Ethical and Practice Issues in Social Action." Social Work 36, no. 2, $122-28$.

Tseng, Wen-Shing, andJing Hsu 1991. Culture and Family: Problems and Therapy. Binghamton, NY: The Haworth Press.

Wichrowski, Mary A. 1996. "Speaking Silence: Some Fieldwork Strategies in Cloistered Communities." Qualitative Sociology 19, no. 1, 153--70.

Wing Sue, Derald, and David Sue. 1990. Counseling the Culturally Different: Theory and Practice, Second Edition. N ew York: John Wiley \& Sons.

Yu, Elena S. H., and William T. Liu. 1986. "Methodological Problems and Policy Implications in Vietnamese Refugee Research." International Migration Review XX, no. 2 (Summer): 483--501. c:J

\section{CRSIYLP PUBLICATIONS BOOKS}

From Being Uprooted to Surviving: Resettlement of the Vietnamese. Chinese "Boat, People" in Montreal, 1980-1990 Lawrence Lam (1996)

Asylum-A w: Gunthe Moral Dilemma with Praeger Plaut (co-published Publishers) $\$ 19.90$

Refugee Rights

Comparativ : Report of a

James C. e Survey

JohnA. Dent d995)y and

Legitimate and illegitimate

Discrhninatio;': New Issues hi

Migration Edited by Howard

Adelman (1995)

$\$ 22.95$

Afric

an Refugees: Development Aid and Repatriation Edited by

Howant Adelman and

John SorenSO!I"I994) \$39.90

Immigration and.J efugee Policy:

Australia and Canada Compared

Edited by Howard Adelman, Lois

Foster, Allan Borowski and Meyer

Burstein (1994)

Volume One: Context, Policy and Implementation \$24.95 Volume

Two: Settlement and Impact \$24.95

Breaking Groun ; :rhe 1956$$
\text { Hungarian Immigrofibert } H \text {. }
$$$$
\text { Canada Edited by Robi }
$$$$
\text { Keyserlingk (1993) }
$$

Taking Refuge: Lao Buddhists in North America Penny Van Esterik (1992) \$12.95

Refuge or Asylum: A Choice for Canada Edited by Howard Adelman and C. Michael Lanphier (1991) $\$ 18.95$

Refugee Policy: Canada and the United States Edited by Howard Adelman (1991) $\$ 20.95$

Soviet-Jewish Emigration and Resettlement in the 1990s Edited by Tanya Basok and Robert J. Brym (1991)

\section{REPORTS}

Paths to Equity: Cultural, Linguistic, and Racial Diversity in Canadian Early Childhood Education Judith Bernhard, Marie Louise Lefebvre etal. (1995) $\$ 18.95$

Cambodian Refugees in Ontario: An Evaluation of Resettlement and Adaptation Janet McLellan (1995) \$12.95

Somali Refugees in Toronto: A Prorde Edward Opoku-Dapaah (1995) \$12.95

Refugee Families and Children: A Directory For Service Providers in Metro Toronto John Morris and Lydia Sawicki (1995) $\$ 6.95$

Adaptation of Ghanaian Refugees in Toronto Edward Opoku-Dapaah (/993) $\$ / 2.50$

Report on the Workshop for African Community Groups in Toronto Edward Opoku-Dapaah (1992) \$12.50

Directory of African Community Groups in Toronto Edward Opoku Dapaah (1992)

\section{OCCASIONAL PAPERS}

Fading Hopes: Struggles for Survival Among Cambodians Repatriated from Thai Refugee Camps Janet McLellan (1996) \$13.95

The Genesis of a Domestic Refugee Regime: The Case of Hungary Edited by Howard Adelman, Endre Sik and Giza Tessenyi (1994) $\$ 14.95$

So That Russia Be "Saved": AntiJewish Violence in Russia, Its Roots and Consequences Tanya Basok and Alexander Benifand (1993)

Please send your orders to:

Centre for Refugee Studies

Yor University

Suite 333. York Lanes

4700 Keele 5 t.

Toronto ON Canada M3J IP3 


\section{REPORIS}

- Somali Refugees in Toronto:

A Profile

By Edward Opoku-Dapaah

ISBN 1-55014-278-x, 130 pp., \$12.95

This is the first comprehensive study of Somali refugees in Toronto. It examines the social, residential, and linguistic characteristic of Somalis, their participation in the local economy, and the activity of Somali community organizations. The report also contains valuable suggestions and recommendations concerning suitable and more efficient service delivery to this community.

- Cambodian Refugees in Ontario:

An Evaluation of Resettlement and

Adaptation

By Janet Mclellan,

ISBN 1-55014-267-4, 142 pp., \$12.95. This major study of Cambodian refugees in Ontario examines the effects of various forms of sponsorship on Cambodian resettlement. It also focuses and the linguistic, economic, educational, training and social dimensions of the whole process of adaptation. The delivery of services by governmental and NGO agencies as well as the effects of the past traumatic experiences of genocide and mass starvation on Cambodian refugees are fully discussed.

- Refugee Families and Children: A

Directory for Service Providers in

Metro Toronto

Compiled by

Dr. John Morris and Lydia Sawicki.

ISBN 1-55014-285-2,39 pp., \$6.95.

This directory is designed for service providers who work with refugee families and children in Metro Toronto. Its aim is to improve service provision through networking and the sharing of training opportunities.

Available from Centre for Refugee Studies

\section{Back Issues of Refuge}

The following is a list of general and thematic issues of Refuge-Canada'speriodica1 on refugees.

1. Environmental Refugees, Vol. 12, No.1. June 1992.

2. Discussion ofImmigration Bill C-86, Vol. 12, No.2, July/(Aug.) 1992.

3. General Issue/Refugee Sponsorship, Vol. 12, No.3, Sept. 1992.

4. Eastern European Refugees, Vol. 12, No.4, Oct. 1992.

The Tragedy of Somalia, Vol. 12, No.5, Nov.lDec. 1992.

The Review of Rejected Refugee Claims in Canada. Vol. 12, No. 6,]an. 1993.

Russia and Central Eurasia, Vol. 12, No.7, February 1993.

8. Africa Issue: Repatriation, Vol. 12, No.8, March 1993.

9. General Issue/Globalization, Vol. 13, No.1, April 1993.

10. Russia and Central Eurasia, Vol. 13, No.2, May 1993.

11. Special Issue on Sri Lanka, Vol. 13, No.3, Jun 1993.

12. Gender Issues and Refugee Law, Vol. 13, No.4, July/Aug. 1993.

13. Southeast Asian Refugees, Vol. 13, No.5, Sept. 1993.

14. Mozambican Refugees, Vol. 13, No.6, Oerober 1993.

15. Russia and Central Eurasia, Vol. 13, No.7, Nov.lDec. 1993.

16. General Issue/Sudan, Vol. 13, No.8, January 1994.

17. Integration of Refugees-The Canadian Experience, Vol. 13, No.9, Feb. 1994.

18. Refugees and Peace in Central America, Vol. 13, No. 10, March 1994.

19. Horn of Africa, Vol. 14, No. 1, April 1994

20. The Russian Federation, Vol. 14, No.2, May 1994.

21. The Former Yugoslavia, Vol. 14, No.3, June/July 1994.

22. General Issue/IRB and RebuiiJing Trust/Tamil Immigrants in Canada, Vol. 14, No.4, Aug.lSept. 1994.

23. Rwandan Crisis, Vol. 14, No.5, Oerober 1994

24. Refugee Resettlement in Israel, Vol. 14, No.6, Nov. 1994

25. Refugee Women-Part 1: Issues, Vol. 14, No.7, Dec. 1994

26. Refugee Women-Part 2: Case Studies, Vol. 14, No.8, Jan. 1995.

27. The Safe Third Country Concept, Vol. 14, No.9, February 1995.

28. Special Issue on Chechnya, Vol. 14, No. 10, March 1995.

29. Reformulation ofInternational Refugee Law, Vol. 15, No.1, 1996.

30. Environment, Development and Refugees, Vol. 15, No.2, 1996.

31. International Intervention in Refugee Crises, Vol. 15, No.3, 1996

32. Early Warning on Humanitarian Crises, Vol. 15, No.4, 1996.

33. Child Refugees, Vol. 15, No.5, 1996.

34. Global Settlement Services, Vol. IS, No.6, 1997.

35. Early Warning and Early Response, Vol. 16, No.1, May 1997.

36. Uprooting and C nsequences, Vol. 16, No.2, June 1997.

37. Development-induced Displacement, VoL 16, No. 3, August 1997.

38. Refugee and Immigrant Women: Anlnternational Perspective, VoL 16, No.4, Ocrober 1997.

Working with Refugees and Internally Displaced Persons, Vol. 16, No.5,

November 1997.

40. Conflict, Population Displacement, and Conflict Resolution, Vol. 16, No.6

December 19

Refugee and I

February 1998. grant Women: An International Perspective. Part II, Vol. 17, No.1,

42. Human Righ

Soviet Un

Single copy: Vol 12, 13 \& 14

(copies); 20 percent discount on 10 1ss

students and exclusively volunteer-run

Please send your orders to:

Centre for Refugee Studies, York University

Suite 333, York Lanes, 4700 Keele Street

Toronto, Ontario, Canada M3J 1 P3

Fax: (416) 736-5837 • Email: refuge@yorku.ca •mswinder@yorku.ca 
Refuge Centre for Refugee Studies Suite 322, York Lanes York University 4700 Keele Street, Toronto Ontario, Canada M3J 1P3 Phone: (416) 7365663 Fax: (416) 736-5837 Email: refuge@yorku.ca

\section{CALL FOR PAPERS}

\section{Refugees as Entrepreneurs in Host Countries}

\section{Guest Editor Sujit Cbowdbury}

This issue of Refuge will explore a more optimistic side of being a refugee since that designation is not an end in itse $£$ Real life experiences will demonstrate how "timdy" refugee statUs has enabled many individuals to develop their potential and become successful in busineS§ politics, science. education, and art in host countries, and Canada, in particular. The role of government programs, local communities, and nongovernmental organizations in JaciUtating this process will be stressed.

Topics addressed in the issue will include:

- the significance of obtaining "timely" refugee

-the role of comprehensive assistance programs and organizations that serve refugees in nurturing refugee

entrepreneurial initiatives;

- the process that connect refugees with opportunities in host countries;

- success stories: refugees as entrepreneurs; politicians, academics, activists, ete; and

- the influence of refi $s$ on the sociopolitical. eC6nomic, and academk life in host countries.

Contributions with shotrled, double-space

about 4000 words. Sho $-t$

on disc or by e-mail. ced, :and reference $\sim$ in the approved Refuge format. They should not exceed 16 pages or

On accepte aussi grt papers of about 900 words are als9 welcome. Word processed submissions may be sent anglais.

Deadline: January 31, 1999.

For further details, please contact:

Marek Swinder, Technical Editor, Refuge (C

Centre for Refugee Studies, York University, Suite

on Refugees)

4700 Keele Street, Toronto, Ontario, Canada M3J

Fax: (416) 736-5837 - Tel:: (416) 736-5843

Email: mswinder@yorku.ca • refuge@yorku.ca 